\title{
Migration and Homing Behavior of Chum Salmon Tagged in the Okhotsk Sea, Eastern Hokkaido
}

\author{
Hayato Saneyoshi ${ }^{1}$, Yousuke Koshino ${ }^{1}$, Hokuto Shirakawa' ${ }^{2}$ Naru Koshida ${ }^{3}$, Yasuyuki Miyakoshi ${ }^{1}$, \\ and Kazushi Miyashita ${ }^{2}$ \\ ${ }^{1}$ Salmon and Freshwater Fisheries Research Institute, Hokkaido Research Organization, 3-373 \\ Kitakashiwagi, Eniwa, Hokkaido 061-1433, Japan \\ ${ }^{2}$ Field Science Center for Northern Biosphere, Hokkaido University, 20-5 Benten Hakodate, Hokkaido 040-0051, \\ Japan \\ ${ }^{3}$ Faculty of Fisheries Science, Hokkaido University, 3-1-1 Minato Hakodate, Hokkaido 041-8611, Japan
}

Keywords: archival tag, chum salmon, tagging, water temperature

Chum salmon (Oncorhynchus keta) is one of the most important species for commercial fisheries in Hokkaido in northern Japan. The Okhotsk coast in eastern Hokkaido is the principal area of salmon production in Japan. Commercial catches of chum salmon have been supported by intensive hatchery programs (Miyakoshi et al. 2013). In Hokkaido, returning chum salmon are fished in coastal waters mainly via set nets that are operated from September to December. Recently, coastal seawater temperatures in autumn have been higher than the historic mean. In years with high coastal seawater temperatures $\left(>20^{\circ} \mathrm{C}\right)$, it has been frequently observed that the peak timing of chum salmon landing was delayed and exploitation rates by coastal set net fisheries were low. In addition, high water temperatures might affect the distribution of chum salmon in coastal areas and the number of fish caught by each set net. In order to determine the effects of seawater temperature on commercial landings, the responses of migrating chum salmon to seawater temperature need to be elucidated.

To understand migration routes, depths, and temperatures experienced by returning chum salmon in the Okhotsk Sea, we caught chum salmon in the coastal waters, applied archival tags to them, and released them in early September 2016 and late August 2017. In this study, we report the outcomes of the tagging experiment for chum salmon in the Okhotsk Sea.

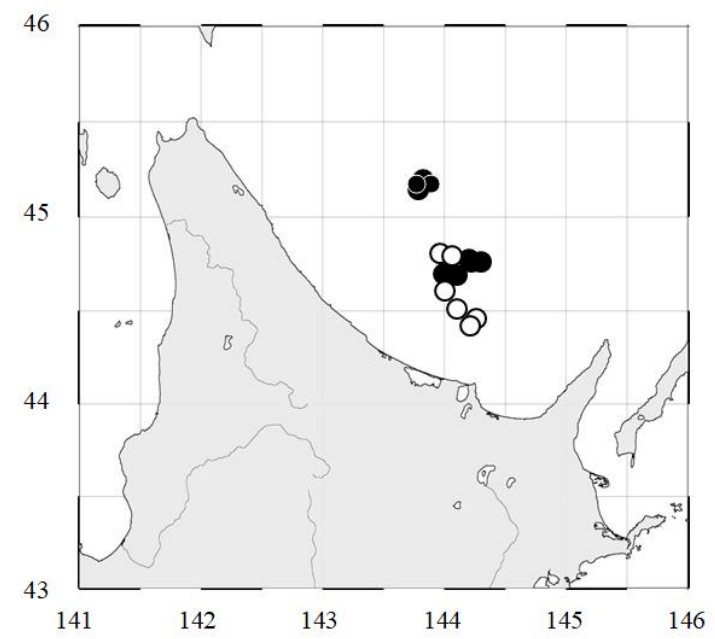

Fig. 1. Map of the sites where the fishing for chum salmon was conducted in the Okhotsk Sea in 2016 (०) and 2017 (•).

From 5-7 September 2016 and 28-30 August 2017, tagging experiments for chum salmon were conducted in the Okhotsk Sea from the research vessel Hokuyo maru (237 tons, Wakkanai Fisheries Research Institute, Hokkaido Research Organization). At a total of eight or nine sites in each year, we visually counted the number of chum salmon and fished for chum salmon at night (Fig. 1). At each site, fishing lights were used, and chum salmon that appeared were fished with a lure with raw bait (a slice of squid or Pacific saury) on the hook. The captured chum salmon were anesthetized, tagged with an archival tag on the base of the dorsal fin, and measured for fork length and 
weight. After recovery from anesthesia, the tagged fish were released into the sea. At the fishing sites, the vertical distributions of the seawater temperature and salinity were measured using CTD (Seabird SBE9plus, Sea-Bird Electronics, Inc., Bellevue, WA, USA).

After release, recaptures of tagged fish were reported by fishermen's cooperative associations when the tagged fish were captured in commercial fisheries or by the Kitami Region Salmon Enhancement Program Association when the tagged fish were recaptured by the weirs that are installed in the rivers for broodstock collection.

In both 2016 and 2017, 14 chum salmon were tagged and released from the research vessel. In 2016, nine pink salmon also were tagged and released. Many chum salmon were counted and caught at sites west of the Kitami-Yamato Bank (approximately $80 \mathrm{~km}$ north of Cape Notoro) in both years and at sites northwest of the Kitami-Yamato Bank (approximately $90 \mathrm{~km}$ northeast of Cape Hinode) in 2017. At the sites where many chum salmon were counted or caught, the sea water temperatures were $15-18^{\circ} \mathrm{C}$ at the surface layer, $5-15^{\circ} \mathrm{C}$ at a depth of $15 \mathrm{~m}$, and $<2^{\circ} \mathrm{C}$ at depths $>50 \mathrm{~m}$.

Of the tagged chum salmon that were released, six and two fish were recaptured in 2016 and 2017, respectively, but no pink salmon were recaptured. In 2016, the tagged fish were recaptured from Shari to Esashi on the Okhotsk coast. The elapsed days from the release were three to 13 days. In 2017, the fish were recaptured in Shari. The elapsed days from the release were nine and 21 days, respectively. Thus, all of the tagged fish were recaptured on the Okhotsk coast.

Some of the tagged fish migrated diurnally between the surface layer and a depth of $200 \mathrm{~m}$. During daylight hours the tagged fish preferred sea water temperatures of $1^{\circ} \mathrm{C}$ at a depth of $200 \mathrm{~m}$. It is considered to regulate their cavity temperature (Azumaya and Ishida 2005). Our study suggests that seawater temperatures are affecting salmon behavior in the coastal areas.

In the Okhotsk Sea off the coast of the Shiretoko Peninsula and Abashiri region, biotelemetry studies were conducted on chum salmon in the 1980s (Soeda et al. 1985; 1987; Shimamura et al. 1987; Yoza et al. 1985). In their papers, many findings on the migratory behavior of chum salmon were reported. We observed many migratory behaviors of chum salmon in our study that were similar to the findings of previous studies. Because the seawater temperatures around Hokkaido in autumn have been higher in recent years, the monitoring of chum salmon behavior relative to climate change is important.

\section{REFERENCES}

Azumaya, T., and Ishida, Y. 2005. Mechanism of body cavity temperature regulation of chum salmon (Oncorhynchus keta) during homing migration in the North Pacific Ocean. Fisheries Oceanography, 14, 81-96.

Miyakoshi, Y., Nagata, M., Kitada, S., and Kaeriyama, M. 2013. Current enhancement program of chum salmon in Hokkaido, Japan. Rev Fish Sci Aquat. 94, 311-323.

Shimamura, T., Yoza, K., Hasegawa, E., Furuta, M., and Soeda, H. 1987. On the swimming behavior of chum salmon in early migratory season off the coast of Abashiri, Hokkaido. Nippon Suisan Gakk, 53, 411-415.

Soeda, H., Yoza, K., Shimamura, T., Hasegawa, E., and Yoshihara, K. 1985. On the vertical moving behavior of chum salmon in early migratory season off the coast of Shiretoko Peninsula. Nippon Suisan Gakk, 51, 14251429.

Soeda, H., Yoza, K., Shimamura, T., and Hasegawa, E. 1987. On the swimming behavior of chum salmon in early migratory season off the coast of Hokkaido, Okhotsk Sea. Nippon Suisan Gakkaishi, 57, 1827-1833.

Yoza, K., Soeda, H., Shimamura, T., Hasegawa, E., and Yoshihara, K. 1985. On the horizontal swimming behavior of chum salmon in early migratory season of the coast of Shiretoko Peninsula. Nippon Suisan Gakk, 51, 14191423. 